\title{
Laser Self-Mixing Sensor for Simultaneous Measurement of Young's Modulus and Internal Friction
}

\author{
Bo Wang, Bin Liu *(D), Lei An, Pinghua Tang, Haining Ji and Yuliang Mao
}

check for

updates

Citation: Wang, B.; Liu, B.; An, L.; Tang, P.; Ji, H.; Mao, Y. Laser Self-Mixing Sensor for Simultaneous Measurement of Young's Modulus and Internal Friction. Photonics 2021, 8, 550. https://doi.org/10.3390/ photonics 8120550

Received: 12 November 2021 Accepted: 1 December 2021 Published: 3 December 2021

Publisher's Note: MDPI stays neutral with regard to jurisdictional claims in published maps and institutional affiliations.

Copyright: (c) 2021 by the authors. Licensee MDPI, Basel, Switzerland. This article is an open access article distributed under the terms and conditions of the Creative Commons Attribution (CC BY) license (https:/ / creativecommons.org/licenses/by/ $4.0 /)$.
School of Physics and Optoelectronics, Xiangtan University, Xiangtan 411105, China; 202021001489@smail.xtu.edu.cn (B.W.); 202021001501@smail.xtu.edu.cn (L.A.); pinghuatang@xtu.edu.cn (P.T.); sdytjhn@xtu.edu.cn (H.J.); ylmao@xtu.edu.cn (Y.M.)

* Correspondence: b1987@uowmail.edu.au

\begin{abstract}
The Young's modulus and internal friction are two important parameters of materials Self-mixing interferometry (SMI) is an emerging non-destructive sensing method that has been employed for various applications because of its advantages of simple structure, ease of alignment and high resolution. Some recent works have proposed the use of SMI technology to measure the Young's moduli and/or internal frictions by measuring the resonance frequencies and damping factors of specimen vibrations induced by impulse excitation. However, the measurement results may be affected by frequencies of SMI fringes, and the implementation requires extra signal processing on SMI fringes. In this work, we developed an all-fiber SMI system without SMI fringes to measure the Young's modulus and internal friction simultaneously. Simulations and experiments were carried out to verify the feasibility of the proposed method. Two specimens of brass and aluminum were tested. The experimental results show that the standard deviations of Young's moduli for brass and aluminum are $0.20 \mathrm{GPa}$ and $0.14 \mathrm{GPa}$, and the standard deviations of internal frictions are $4.0 \times 10^{-5}$ and $5.4 \times 10^{-5}$, respectively. This method eliminates the influences of the SMI fringe frequency on the resonant frequency and requires no signal processing on SMI fringes, contributing to its simplicity as a method for the measurement of the Young's modulus and internal friction.
\end{abstract}

Keywords: self-mixing interferometry; optical feedback interferometry; Young's modulus; internal friction; laser diode; laser sensor

\section{Introduction}

The Young's modulus and internal friction are two important parameters for mechanical and material engineering [1]. The Young's modulus describes the capacity of a material to resist deformation, which is defined as the ratio of stress to strain during the elastic loading. It is one of the most important and widely used parameters of materials to evaluate their compressive strength, flexural strength and porosity. Internal friction is often used to evaluate the dissipation of vibration energy in the specimen, which can be used in process control as additional information to the resonant frequency [1,2]. Hence, the determination of the Young's modulus and/or internal friction has attracted much attention, and different approaches have been developed to measure them. The conventional methods include tensile testing [3], flexural testing [4], indentation testing [5], etc., which are usually performed by directly measuring the deformation of the material sample under a known force. These methods are often called static methods, which may cause fatigue and damage to the materials after repeated measurements for a specimen. As a result, more interests have been given to the dynamic methods.

The impulse excitation technique (IET) is one of the typical dynamic methods used for measuring the Young's modulus and internal friction, which has the merits of being non-destructive and having high accuracy; it is often implemented by microphone, accelerometer and so on [1,6]. Recently, an optical-based IET method was developed for the measurement of the Young's modulus [7] and internal friction [8]; in this method, 
self-mixing interferometry (SMI) technology was applied. In [7], the Young's modulus was measured by obtaining the resonant frequency of the specimen via SMI technology. In [8], the Young's modulus and internal friction were measured by applying continuous wavelet transform on the SMI signals. Due to the existence of SMI fringes, the frequency components corresponding to SMI fringes exist together with resonant frequency, which may hinder the determination of the resonant frequency and additionally the Young's modulus. Moreover, extra signal processing for SMI fringes is required, which may lead to the implementation being relatively complex and time-consuming.

SMI is an emerging non-destructive sensing method with many advantages, such as the measurement system being compact and simple, the implementation cost being low and measurement resolution being high [9]; it has been employed for various applications, such as the measurement of displacement [10-12], distances [13-15], velocities [16,17], vibrations [18,19], and angles [20,21], and the characterization of micro-machined silicon gyroscopes [22]. It usually consists of a laser diode (LD), a photodiode integrated inside the laser package, a lens and a target to be measured [23], which reflects a minimum-part-count sensing scheme. SMI-based sensing is often used to measure the phase change in an SMI signal with a fringe pattern that is sinusoidal or saw-tooth-like. The phase is called an optical phase in the external cavity that is linked to the quantity to be measured, e.g., displacement and distance. Each SMI fringe maps to a half-laser-wavelength displacement of the target. It was demonstrated that some fringes may be lost or even totally disappear with the increase in the optical feedback level [9]. When the SMI fringes totally disappear, the output of SMI signal may closely replicate to the initial optical phase if no coherent collapse or chaos appears [9], which may contribute linear sensing being possible. Some applications based on this kind of linear sensing state have been developed, e.g., the measurement of relative displacement [24], and acoustic emission [25]. This state fits well with the measurement of the Young's modulus and internal friction. Therefore, in this work, we intend to measure Young's modulus and internal friction by using the SMI technology without typical SMI fringes. In this case, there is no need for signal processing on the SMI fringes. The influence of the SMI fringe frequency on the resonant frequency will be eliminated and the measurement performance is expected to be improved.

\section{Measurement Principle}

\subsection{The Equations for Young's Modulus and Internal Friction}

The specimen will suffer from damping vibration with resonant frequency $\left(f_{R O}\right)$ after impulse excitation by steel-ball-dropping or singular strike if it is designed it with proper geometric dimensions [7]. The stimulated damping vibration can be expressed as shown below:

$$
y(t)=A_{0} e^{-\kappa t} \cos \left(2 \pi f_{R O} t\right),
$$

where $A_{0}$ is the original amplitude of the vibration, which is decided by the strength of the impulse excitation, and $k$ is the exponential damping factor.

According to standard released by ASTM E1876-01 [26], the Young's modulus can be calculated if the geometric dimensions, mass and resonant frequency of the specimen are known. The relationship between the Young's modulus (denoted by $E$ ) and resonant frequency $f_{R O}$ is expressed as follows when the specimen is rectangular, as shown in Figure 1.

$$
E=0.9465 \cdot \frac{m f_{R O}^{2} L^{3}}{b h^{3}} \cdot T,
$$

where $m$ is the mass of the specimen; $L, b$ and $h$ are the length, width and height respectively. Furthermore, $T$ is the correction factor with $T=1+6.585(h / L)^{2}$. Hence, the Young's modulus can be obtained if the $f_{R O}$ of specimen can be extracted from the SMI signal. Additionally, with the damping factor obtained, the internal friction $Q^{-1}$ of the tested sample can be calculated as [1]:

$$
Q^{-1}=\frac{k}{\pi f_{R O}}
$$




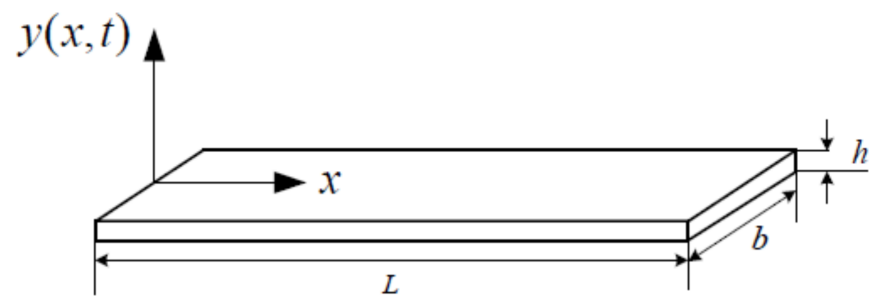

Figure 1. The geometric dimensions of the testing specimen.

\subsection{The Sensing Principle of SMI}

The sensing mechanism of an SMI system is based on the self-mixing effect in a laser. To ensure similarity to Michelson interferometry, the laser intensity in an SMI system is modulated in the form of interference fringes when a part of the laser is reflected by an external target and reenters the laser internal cavity and mixes with internal-cavity laser [9]. When the specimen is stimulated to vibrate via impulse excitation, the optical path and optical phase will be changed, and thus, an SMI signal can be generated. Figure 2 presents the schematic diagram of a typical free-space SMI system.

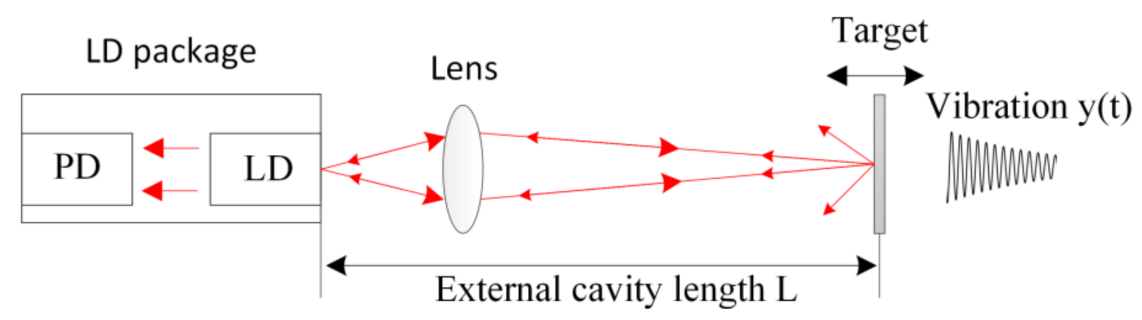

Figure 2. Schematic diagram of a typical free-space SMI system.

The widely accepted mathematical model for SMI sensing system can be derived from the well-known Lang-Kobayashi Equations [27], as shown below:

$$
\begin{gathered}
\phi_{0}(t)=4 \pi L(t) / \lambda_{0}, \\
\phi_{F}(t)=\phi_{0}(t)-C \sin \left[\phi_{F}(t)+\arctan (\alpha)\right], \\
G(t)=\cos \phi_{F}(t), \\
P(t)=P_{0}[1+m G(t)],
\end{gathered}
$$

where $\phi_{0}(t)$ and $\phi_{F}(t)$ are the emitted light phase of LD without and with optical feedback, respectively; $t$ is the time index. In Equation (4), $L(t)$ is the length of the external cavity, i.e., the distance from the output facet of the LD to the external target; $\lambda_{0}$ is the wavelength of the emitted light of LD without optical feedback; $\alpha$ is the linewidth enhancement factor. The $G(t)$ is the SMI signal function in Equation (6), which shows that $G(t)$ will modulate the output power of the laser, denoted by $P(t)$, when $\phi_{0}(t)$ varies. Furthermore, in Equation (7), $P_{0}$ is the emitted power of LD without optical feedback, and $m$ is the power modulation index. The optical feedback factor $C$ is defined as below [28,29]:

$$
C=\eta \frac{\tau}{\tau_{L D}}\left(1-R_{2}\right) \sqrt{\frac{R_{3}}{R_{2}}} \sqrt{1+\alpha^{2}},
$$

where $R_{2}, R_{3}$ are the power reflectivities of the laser-emitting facet and the external target, respectively, $\eta$ is the coupling coefficient, $\tau_{L D}$ is the internal round-trip time in the LD, and $\tau$ is the external round-trip time of the light transmitting in the external cavity, which is expressed as $\tau=2 n L(t) / c$ ( $n$ is the refractive index of the external cavity, $c$ is the speed of light transmitting in the vacuum). We usually take $G(t)$ as the SMI signal because it can be normalized from the laser output power $P(t)$. 
According the commonly used definition in the community, an SMI system operates in weak feedback regime when the optical feedback factor $C \leq 1$, whereas it is in a moderate/strong feedback regime if $C>1$ [9]. In a weak feedback regime, the SMI signals show symmetric or distorted sinusoidal shape. In a moderate/strong feedback regime, they will be sawtooth-like and the loss of fringes may happen [25]. When the optical feedback factor increases to a certain value, SMI fringes may totally disappear. The shape of the SMI signals may closely replicate the original phase stimulus signal if no coherent collapse or chaos occurs [9], which contributes to linear sensing without the need for SMI fringe processing to be possible. Typical SMI signals with different optical feedback factor are shown in Figure 3, which are derived from the same harmonic vibration signal with different optical feedback factors. Figure $3 a$ is the vibration signal, Figure $3 b-\mathrm{d}$ are the corresponding SMI signals with $C=0.8, C=3.0$, and $C=20.0$, respectively. It can be seen that the SMI fringes are clearly presented in Figure $3 b, c$, whereas there are no SMI fringes in Figure 3d. Figure $3 \mathrm{~d}$ is the state we used to measure the Young's modulus and internal friction. When impulse excitation is applied on the specimen by ball-dropping or strick, the specimen vibrates with resonant frequency. In this case, the external cavity length $L(t)$ can be expressed as $L(t)=L_{0}+y(t)$ where $L_{0}$ is the initial external cavity length and $y(t)$ is the vibration of the specimen. Then, SMI signals such as those in Figure $3 \mathrm{~d}$ will be generated and captured. Then resonant frequency and damping factor are obtained. The Young's modulus and internal friction are finally calculated with Equations (2) and (3), respectively.

(a)

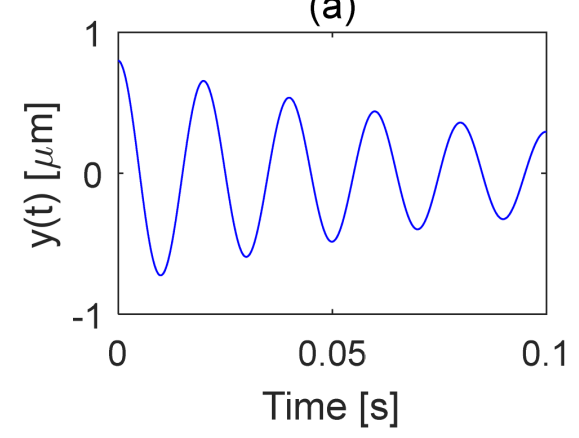

(c)

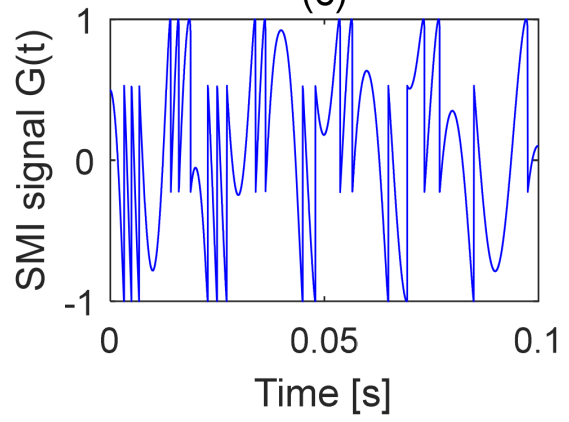

(b)

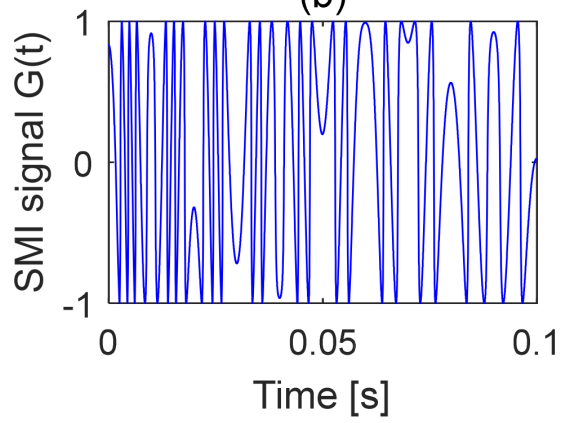

(d)

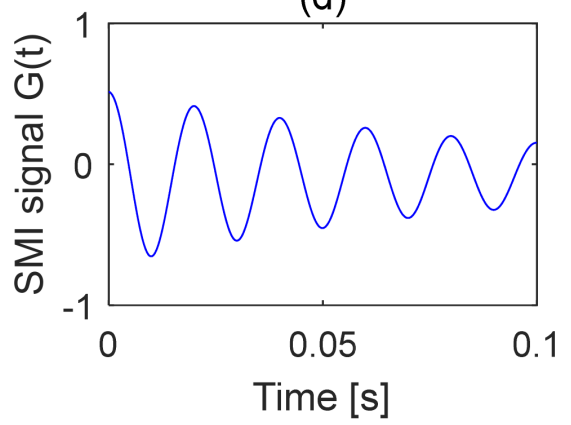

Figure 3. SMI signal with different optical feedback factors: (a) the initial vibration; (b-d) SMI signal with $C=0.8, C=3.0, C=20.0$, respectively.

\section{Results}

\subsection{Simulation}

To verify the feasibility of the proposed method, we first performed simulations. In the simulations, the parameters with the specimen were adapted from [7]. We set the damping vibration as $y(t)=1.5 e^{-4.60 t} \cos (2 \pi * 444 t) \mu \mathrm{m}$. Simulating the SMI model, we obtained the results as shown in Figure 4. The right column includes the results of the proposed method and the left column shows those obtained using method in [7]. Here, Figure 4a,e are the vibration signals of the specimen. Figure $4 b, f$ are the SMI signals. In order to show 
the details, we zoomed in the parts from $0.05 \mathrm{~s}$ to $0.06 \mathrm{~s}$ in Figure $4 \mathrm{~b}, \mathrm{f}$, which are shown in Figure $4 \mathrm{c}, \mathrm{g}$. It can be seen that in Figure 4g, there is no fringe in the SMI signals. Figure 4d, h are the corresponding magnitude spectra obtained via Fast Fourier transform (FFT). It can be clearly seen that Figure $4 \mathrm{~h}$ shows a clear spectrum line corresponding to the resonant frequency with $f_{R O}=444 \mathrm{~Hz}$. In Figure $4 \mathrm{~d}$, there are many frequency components, which makes it difficult to distinguish the resonant frequency. Using the resonant frequency from Figure 4h, the Young's modulus could be calculated with Equation (2).
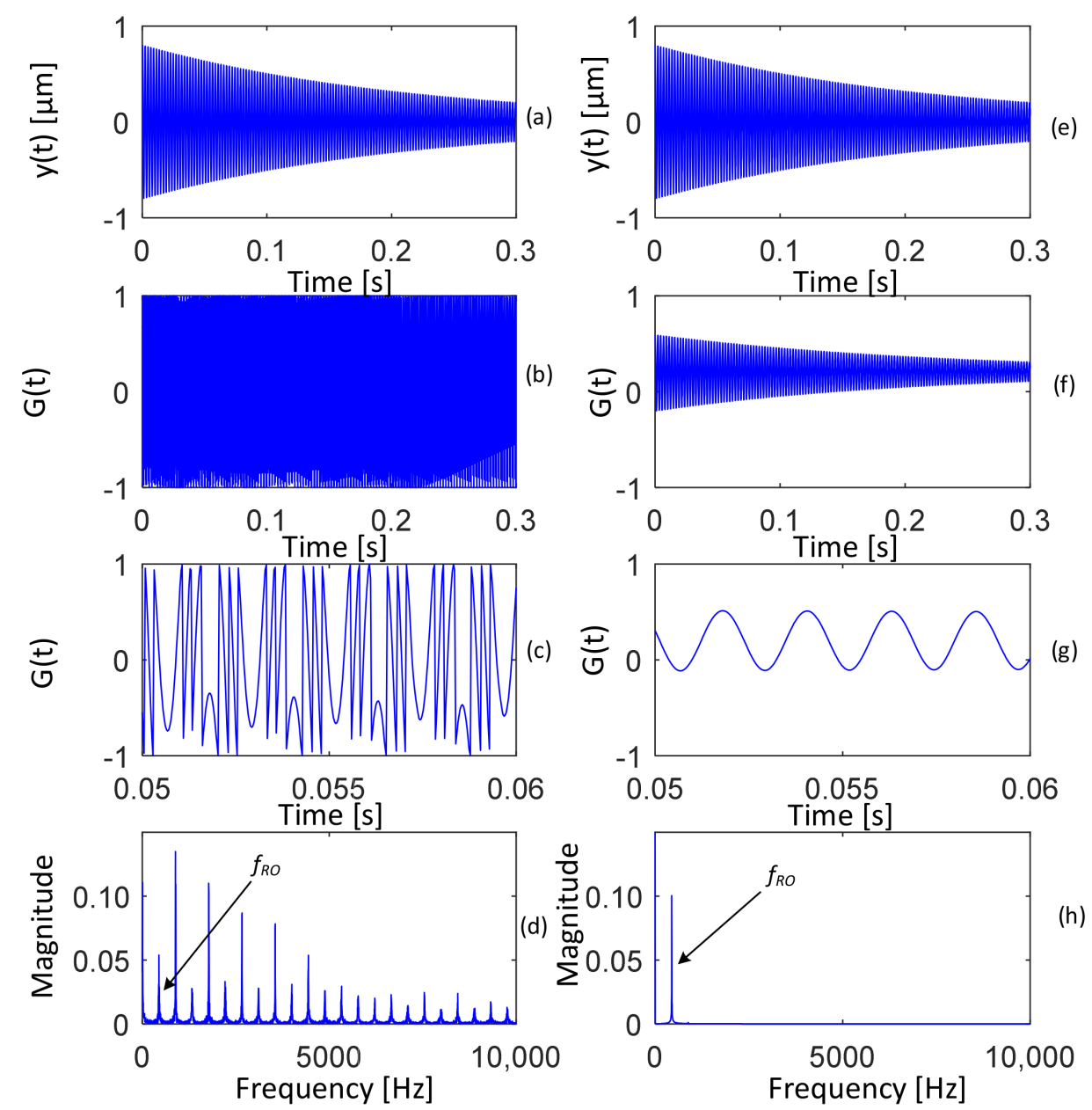

Figure 4. Simulation results, $(\mathbf{a}, \mathbf{e})$ the vibrations of the specimen; $(\mathbf{b}, \mathbf{f})$ SMI signals; $(\mathbf{c}, \mathbf{g})$ the zoomed part from $0.05 \mathrm{~s}$ to $0.06 \mathrm{~s}$ in $(\mathbf{b}, \mathbf{f})$, respectively, $(\mathbf{d}, \mathbf{h})$ the FFT results of $(\mathbf{b}, \mathbf{f})$, respectively.

To calculate the internal friction $Q^{-1}$, we needed to obtain the exponential damping factor $k$ except for resonant frequency $f_{R O}$ according to Equation (3). For the proposed method in this work, the SMI signals closely replicated the damping vibration, as in Figure 4f. Hence, we collected the local peak points in the SMI signals, and conducted curve fitting for these peak points using an exponential function to obtain the damping factor. Figure 5 presents the curve fitting results of the SMI signals in Figure $4 \mathrm{f}$, from which we could obtain the damping factor with $k=4.61 \mathrm{~s}^{-1}$, which was consistent with the preset value. Once we obtained the vales of the resonant frequency and damping factor, the internal friction was able to be calculated with $Q^{-1}=0.0033$ using Equation (3). 


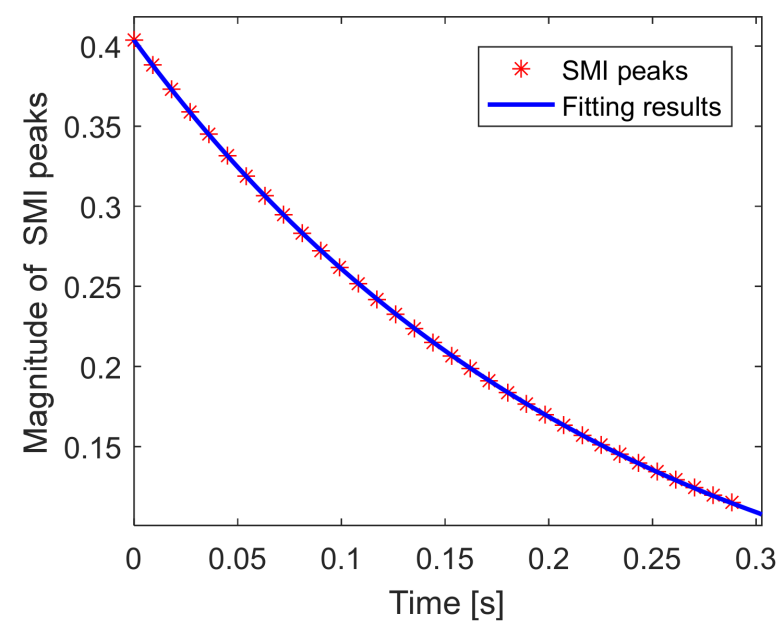

Figure 5. Curve fitting result of SMI signals without fringes.

\subsection{Experiment}

In order to make the SMI system operate in a linear sensing state and avoid the occurrence of coherent collapse or chaos, we followed the requirements in [25] to build our experimental system, as shown in Figure 6. An all-fiber SMI system was built in this work. The laser was a fiber-coupled DFB laser diode (Thorlabs, LP1550-SAD2), which was driven by a LD controller (Thorlabs, ICT4001). The laser operates with a pumping current of $25 \mathrm{~mA}$. In the experiments, the temperature of the laser was stabilized at $25 \pm 0.01{ }^{\circ} \mathrm{C}$. A photodiode (PD) integrated within the LD package was used to transfer the SMI intensity into electric signals, which was followed by a detection circuit. In order to obtain a high feedback level, we used an FBG as the external target, which had a power reflectivity of $50 \%$ and an FWHM of $0.5 \mathrm{~nm}$. Note that the FBG could be replaced by film with high reflectivity coated on the optical fiber facet. A $10.0 \mathrm{~cm}$ fiber with the FBG was affixed on the specimen to sensing the vibration induced by impulse excitation achieved by singular strike. The total length of the fiber in the system was $100.0 \mathrm{~cm}$. A digital oscilloscope was used to capture the SMI signals.

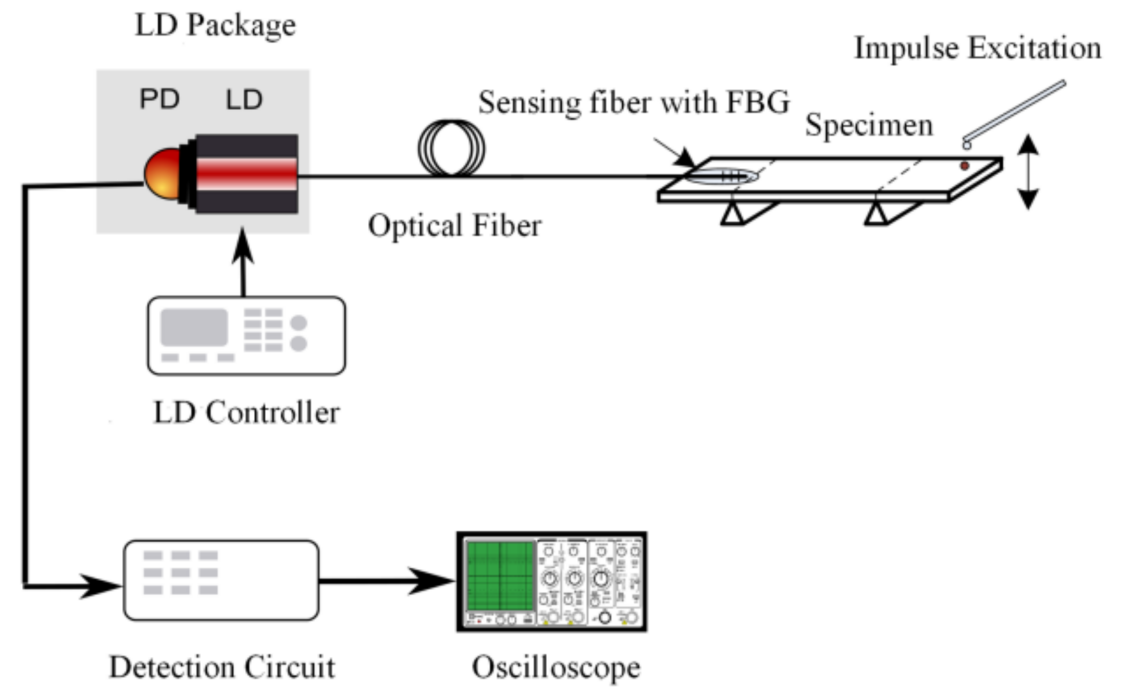

Figure 6. Experiment setup for measurement of Young's modulus and internal friction.

In the experiments, we tested two specimens of brass and aluminum 6061. For each specimen, we tested 10 times. The brass specimen had $L=138.35 \mathrm{~mm}, b=12.06 \mathrm{~mm}$, $h=2.23 \mathrm{~mm}$ and $m=30.65 \mathrm{~g}$ and the aluminum specimen had $L=132.43 \mathrm{~mm}, b=12.24 \mathrm{~mm}$, $h=2.00 \mathrm{~mm}$ and $m=8.70 \mathrm{~g}$. Figure 7 shows an example of the experimental SMI signal 
for the brass specimen, where Figure 7a includes the SMI signals and Figure $7 \mathrm{~b}$ illustrates the zoomed-in signal of the rectangular area in Figure 7a. Figure 7c shows the FFT results of Figure 7a. Note that the sampling frequency in the experiments was $500 \mathrm{kHz}$, and 500,000 samples were captured for each SMI signal. It can be clearly seen that the resonant frequency was $452 \mathrm{~Hz}$. Figure $7 \mathrm{~d}$ shows the curve fitting result, from which we obtained the damping factor of $k=1.10 \mathrm{~s}^{-1}$. Based on Equations (2) and (3), the Young's modulus and internal friction were calculated with $E=117.4 \mathrm{GPa}$ and $Q^{-1}=7.8 \times 10^{-4}$.
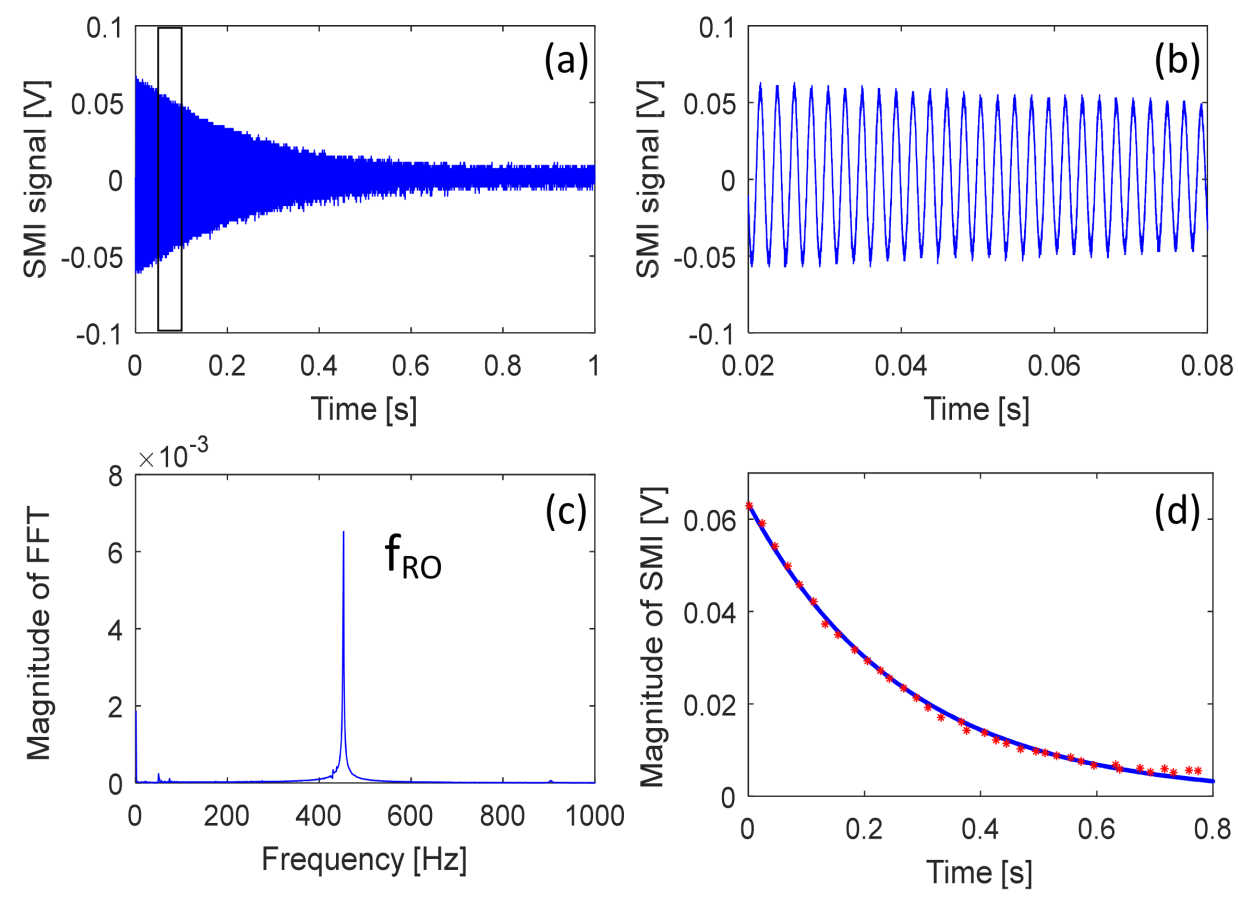

Figure 7. Example of the experiment results for brass specimen, (a) observed SMI signal, (b) zoomedin SMI signals, (c) FFT magnitude spectrum, (d) curve fitting results.

Table 1 presents the overall experimental measurement results. It can be seen that the average values of the Young's modulus for brass and aluminum were $117.9 \mathrm{GPa}$ and 69.4 GPa with standard deviations of $0.20 \mathrm{GPa}$ and $0.14 \mathrm{GPa}$, respectively. The internal frictions of the brass and aluminum specimen were 0.00080 and 0.00174 with standard deviations of $4.0 \times 10^{-5}$ and $5.4 \times 10^{-5}$, respectively. The results are consistent with the ones in [7].

Table 1. Experimental measurement results.

\begin{tabular}{ccccc}
\hline \multicolumn{1}{c}{ Specimen } & \multicolumn{2}{c}{ Brass } & \multicolumn{2}{c}{ Aluminum } \\
\hline \multirow{2}{*}{ Parameters } & $\begin{array}{c}\text { Average } \\
\text { Value }\end{array}$ & $\begin{array}{c}\text { Standard } \\
\text { Deviation }\end{array}$ & $\begin{array}{c}\text { Average } \\
\text { Value }\end{array}$ & $\begin{array}{c}\text { Standard } \\
\text { Deviation }\end{array}$ \\
\hline Resonant frequency $f_{R O}$ & $453 \mathrm{~Hz}$ & $0.50 \mathrm{~Hz}$ & $596 \mathrm{~Hz}$ & $0.60 \mathrm{~Hz}$ \\
Damping factor $k$ & $1.14 \mathrm{~s}^{-1}$ & $0.04 \mathrm{~s}^{-1}$ & $3.25 \mathrm{~s}^{-1}$ & $0.10 \mathrm{~s}^{-1}$ \\
Young's modulus $E$ & $117.9 \mathrm{GPa}$ & $0.20 \mathrm{GPa}$ & $69.4 \mathrm{GPa}$ & $0.14 \mathrm{GPa}$ \\
Internal friction $Q^{-1}$ & 0.00080 & $4.0 \times 10^{-5}$ & 0.00174 & $5.4 \times 10^{-5}$ \\
\hline
\end{tabular}

\section{Discussion}

Both the simulation and experiment results verified the feasibility of the proposed method. The proposed method eliminates the influence of fringe frequency on the resonant frequency and requires no complex signal processing on the SMI fringes as compared with those outlined in $[7,8]$. The required optical feedback level factor is often large in order to make the system operate in the sensing state without SMI fringes. However, a large 
feedback level factor may lead to the LD being unstable or even entering a chaotic state [30], which may degrade the measurement performance or even cause the proposed method to be invalid. As a result, proper operations should be set. Detailed descriptions of the operation requirements are not within the scope of this work, but they can be found by referring to our previous work [25]. It is also noteworthy that the Young's moduli and internal frictions of materials are usually temperature-dependent [1]. In this work, the experimental measurements were conducted at room temperature and we assumed that the temperature of the specimens during the measurement was not changed. Although the operation temperature of the LD was stabilized with the LD controller, the temperature of the specimens may have experienced slight fluctuations. The temperature dependence of the measurement will be investigated in future works.

\section{Conclusions}

We presented a new simple method to measure the Young's modulus and internal friction of material using IET and SMI technologies. We used SMI technology in a strong feedback regime without fringes to extract the resonant frequency and exponential damping factor of the damping vibration induced by IET on the material specimen. The resonant frequencies were determined by FFT on the SMI signals. The exponential damping factors were obtained by curve fitting on the local peak points of the SMI signals. Simulations and experiments were carried out to verify the feasibility of the proposed method. Two material specimens (brass and aluminum) were tested. The experimental results show that standard deviations of Young's moduli for brass and aluminum are $0.20 \mathrm{GPa}$ and $0.14 \mathrm{GPa}$, and the standard deviations of internal frictions are $4.0 \times 10^{-5}$ and $5.4 \times 10^{-5}$, respectively. This method eliminates the influences of fringe frequency on the resonant frequency and requires no complex signal processing on the SMI fringes, contributing to its simplicity as method for the measurement of the Young's modulus and internal friction.

Author Contributions: Conceptualization, B.W. and B.L.; methodology, B.W. and B.L.; software, B.W. and B.L.; validation, B.W., B.L. and L.A.; writing — original draft preparation, B.W.; writing-review and editing, B.L., L.A., P.T., H.J. and Y.M., visualization, B.W. and B.L.; supervision, B.L.; funding acquisition, B.L. All authors have read and agreed to the published version of the manuscript.

Funding: This research was funded by the National Natural Science Foundation of China, grant numbers 62005234 and 51902276 the Scientific Research Foundation of Hunan Provincial Education Department, grant number 20C1791, and the Natural Science Foundation of Hunan province, grant number 2019JJ50583. The APC was funded by the National Natural Science Foundation of China, grant number 62005234.

Institutional Review Board Statement: Not applicable.

Informed Consent Statement: Informed consent was obtained from all subjects.

Data Availability Statement: The data presented in this study are available on request from the corresponding author. The data are not publicly available since the data also forms parts of an ongoing study.

Conflicts of Interest: The authors declare no conflict of interest.

\section{References}

1. Roebben, G.; Bollen, B.; Brebels, A.; Van Humbeeck, J.; Van der Biest, O. Impulse excitation apparatus to measure resonant frequencies, elastic moduli, and internal friction at room and high temperature. Rev. Sci. Instrum. 1997, 68, 4511-4515. [CrossRef]

2. Xie, M.; Ding, G.; Jiang, M.; Li, F. High-frequency elastic moduli and internal frictions of $\mathrm{Zr}_{41.2} \mathrm{Ti}_{3.8} \mathrm{Cu}_{12.5} \mathrm{Ni1} \mathrm{Be}_{22.5}$ bulk metallic glass during glass transition and crystallization. J. Non-Cryst. Solids 2021, 560, 120754. [CrossRef]

3. Lord, J.D.; Morrell, R.M. Elastic modulus measurement-Obtaining reliable data from the tensile test. Metrologia 2010, 47, S41-S49. [CrossRef]

4. Shetty, D.K.; Rosenfield, A.R.; McGuire, P.; Bansal, G.K.; Duckworth, W.H. Biaxial flexure tests for ceramics. Am. Ceram. Soc. Bull. 1980, 59, 1193-1197.

5. Suansuwan, N.; Swain, M.V. Determination of elastic properties of metal alloys and dental porcelains. J. Oral Rehabil. 2001, 28, 133-139. [CrossRef] [PubMed] 
6. Schmidt, R.; Alpern, P.; Tilgner, R. Measurement of the Young's modulus of moulding compounds at elevated temperatures with a resonance method. Polym. Test. 2005, 24, 137-143. [CrossRef]

7. Lin, K.; Yu, Y.; Xi, J.; Li, H.; Guo, Q.; Tong, J.; Su, L. A Fiber-Coupled Self-Mixing Laser Diode for the Measurement of Young's Modulus. Sensors 2016, 16, 928. [CrossRef]

8. Xia, F.; Liu, B.; Cao, L.; Yu, Y.; Xi, J.; Guo, Q.; Tong, J. Experimental study on simultaneously measuring Young's modulus and internal fraction using self-mixing system. In Semiconductor Lasers and Applications VIII, (International Society for Optics and Photonics; SPIE: Beijing, China, 2018; p. 1081212.

9. Taimre, T.; Nikolić, M.; Bertling, K.; Lim, Y.L.; Bosch, T.; Rakić, A.D. Laser feedback interferometry: A tutorial on the self-mixing effect for coherent sensing. Adv. Opt. Photonics 2015, 7, 570-631. [CrossRef]

10. Amin, S.; Zabit, U.; Bernal, O.D.; Hussain, T. High Resolution Laser Self-Mixing Displacement Sensor under Large Variation in Optical Feedback and Speckle. IEEE Sens. J. 2020, 20, 9140-9147. [CrossRef]

11. Guo, D.; Shi, L.; Yu, Y.; Xia, W.; Wang, M. Micro-displacement reconstruction using a laser self-mixing grating interferometer with multiple-diffraction. Opt. Express 2017, 25, 31394-31406. [CrossRef]

12. Zhu, D.; Zhao, Y.; Tu, Y.; Li, H.; Xu, L.; Yu, B.; Lu, L. All-fiber laser feedback interferometer using a DBR fiber laser for effective sub-picometer displacement measurement. Opt. Lett. 2021, 46, 114-117. [CrossRef]

13. Guo, D.; Wang, M. Self-mixing interferometry based on a double-modulation technique for absolute distance measurement. Appl. Opt. 2007, 46, 1486-1491. [CrossRef]

14. Norgia, M.; Melchionni, D.; Pesatori, A. Self-mixing instrument for simultaneous distance and speed measurement. Opt. Lasers Eng. 2017, 99, 31-38. [CrossRef]

15. Zhao, Y.; Wang, C.; Zhao, Y.; Zhu, D.; Lu, L. An All-Fiber Self-Mixing Range Finder with Tunable Fiber Ring Cavity Laser Source. J. Light. Technol. 2021, 39, 4217-4224. [CrossRef]

16. Chen, J.; Zhu, H.; Xia, W.; Guo, D.; Hao, H.; Wang, M. Self-mixing birefringent dual-frequency laser Doppler velocimeter. Opt. Express 2017, 25, 560-572. [CrossRef] [PubMed]

17. Zhang, X.; Gu, W.; Jiang, C.; Gao, B.; Chen, P. Velocity measurement based on multiple self-mixing interference. Appl. Opt. 2017, 56, 6709-6713. [CrossRef]

18. Usman, M.; Zabit, U.; Bernal, O.D.; Raja, G.; Bosch, T. Detection of Multimodal Fringes for Self-Mixing-Based Vibration Measurement. IEEE Trans. Instrum. Meas. 2019, 69, 258-267. [CrossRef]

19. Zabit, U.; Bony, F.; Bosch, T.; Rakić, A.D. A Self-Mixing Displacement Sensor with Fringe-Loss Compensation for Harmonic Vibrations. IEEE Photonics Technol. Lett. 2010, 22, 410-412. [CrossRef]

20. Wang, C.; Fan, X.; Guo, Y.; Gui, H.; Wang, H.; Liu, J.; Yu, B.; Lu, L. Full-circle range and microradian resolution angle measurement using the orthogonal mirror self-mixing interferometry. Opt. Express 2018, 26, 10371-10381. [CrossRef] [PubMed]

21. Zhao, Y.; Fan, X.; Wang, C.; Lu, L. An improved intersection feedback micro-radian angle-measurement system based on the Laser self-mixing interferometry. Opt. Lasers Eng. 2020, 126, 105866. [CrossRef]

22. Annovazzi-Lodi, V.; Merlo, S.; Norgia, M. Measurements on a micromachined silicon gyroscope by feedback interferometry. IEEE/ASME Trans. Mechatron. 2001, 6, 1-6. [CrossRef]

23. Yu, Y.; Xi, J.; Chicharo, J.F. Measuring the feedback parameter of a semiconductor laser with external optical feedback. Opt. Express 2011, 19, 9582-9593. [CrossRef] [PubMed]

24. El Assad, J.; Bosch, T.; Plantier, G. Laser Diode Under Strong Feedback for Mechatronics Applications. In Proceedings of the SENSORS, 2007 IEEE, Atlanta, GA, USA, 28-31 October 2007; pp. 387-390.

25. Liu, B.; Ruan, Y.; Yu, Y. All-Fiber Laser-Self-Mixing Sensor for Acoustic Emission Measurement. J. Light. Technol. 2021, 39, 4062-4068. [CrossRef]

26. ASTM. ASTM E1876 01, Standard Test Method for Dynamic Young's Modulus, Shear Modulus, and Poisson's Ratio by Impulse Excitation of Vibration; ASTM International: West Conshohocken, PA, USA, 2005; Available online: https://www.astm.org/Standards/E187 6.htm (accessed on 11 February 2005).

27. Donati, S.; Giuliani, G.; Merlo, S. Laser diode feedback interferometer for measurement of displacements without ambiguity. IEEE J. Quantum Electron. 1995, 31, 113-119. [CrossRef]

28. Yu, Y.; Xi, J.; Chicharo, J.F.; Bosch, T.M. Optical Feedback Self-Mixing Interferometry with a Large Feedback Factor C: Behavior Studies. IEEE J. Quantum Electron. 2009, 45, 840-848. [CrossRef]

29. Liu, B.; Ruan, Y.; Yu, Y.; Xi, J.; Guo, Q.; Tong, J.; Rajan, G. Laser Self-Mixing Fiber Bragg Grating Sensor for Acoustic Emission Measurement. Sensors 2018, 18, 1956. [CrossRef]

30. Donati, S. Developing self-mixing interferometry for instrumentation and measurements. Laser Photonics Rev. $2012,6,393-417$. [CrossRef] 